\title{
Effects of two utility-scale solar energy plants on land-cover patterns using SMA of Thematic Mapper data
}

3 Mohammad Masih Edalat ${ }^{\mathrm{a}}$, Haroon Stephen $^{\text {ab }}$

$4 \quad{ }^{a}$ Department of Civil and Environmental Engineering and Construction, University of Nevada, Las Vegas, $5 \quad$ United States

$6 \quad{ }^{b}$ Director GIS and Remote Sensing Core Lab, University of Nevada, Las Vegas, United States

7 Abstract

8 Due to depleting fossil fuels, many nations are adding renewable resources - such as geothermal, 9 wind, and solar energy - to their energy portfolios. The southwestern United States counts as one 10 of the best places in the world to collect solar energy, and already, Nevada is harnessing the sun's 11 energy on a large scale. Depending on the size and type of the installation and location, there can

12 be various environmental implications due to changes in the land cover change, and sometimes 13 these are potentially negative implications. This study was conducted at two utility-scale solar 14 energy (USSE) plants in Nevada, Nevada Solar One and the Nellis Solar Power Plant. First, the 15 environmental effects of USSE are reviewed. Second, changes in land cover were analyzed for 16 pre-installation, syn-installation, and post-installation in these two facilities from 2004 to 2011. A

17 time series of Landsat 5 thematic mapping (TM) images were used with principal component 18 analysis (PCA), minimum noise fraction (MNF), and spectral mixture analysis (SMA) to estimate 19 the subpixel fraction of each pixel covered by a four-endmember model: high-albedo, low-albedo, 20 shadow, and vegetation. Results showed that PCA-Normalized data had the highest correlation 21 coefficients, which indicates that solar plant construction had no significant effect on the land22 cover fraction in the surrounding area of the facilities. On the other hand, results of land-cover 23 analysis of the points located within the facilities showed that the low-albedo fraction increased 
24 and the high-albedo fraction decreased after construction. The shadow fraction decreased slightly

25 after construction, and the fraction of vegetation was close to zero before and after construction;

26 this was due to the plants being constructed in an arid area. This study indicated that except for the

27 long-term effects of USSE plants on the environment, land-cover patterns in the case of high-

28 albedo, low-albedo, shadow, and vegetation altered significantly inside plant areas and did not

29 alter significantly outside.

\section{Keywords}

31 Solar energy, Land-cover change, Environmental impacts, PCA, MNF, SMA,

\section{1. Introduction}

34 With the awareness that fossil fuels are depleting, many nations are adding renewable resources

35 to their energy portfolios, such as geothermal, wind, and solar energy. Although harvesting solar

36 energy has been around for a while, not until recently has this topic gained interest as a

37 renewable energy resource, especially in areas having bright sunshine year-round. The

38 southwestern United States counts as one of the most attractive places in the world to collect

39 solar energy. Already, Nevada is harnessing this energy on a large scale, and several utility-scale

40 solar energy (USSE) plants have emerged that typically are capable of greater than 1 MW.

41 According to the Solar Energy Industries Association report in 2014, among the U.S.

42 states, Nevada produces 286 watts per person, and stands in the third place after Hawaii and

43 Arizona [1]. Due to its numerous USSE plants, Nevada is emerging among the top states in terms

44 of solar opportunities. These USSE plants, which use varying types of solar farming

45 technologies, generally can be classified into photovoltaic (PV) and concentrating solar power

46 (CSP) [2]. PV cells generate electrical power by converting sunlight into direct current 
47 electricity. On the other hand, CSP technologies use mirrors or reflective surfaces to reflect and

48 concentrate sunlight onto receivers, which collect the solar energy and convert it to heat.

49 Devabhaktuni et al., [3] reviewed various solar power technologies, their applications and

50 challenges. Since these technologies at the utility scale have a large spatial footprint, it is

51 important to understand their potential effects on the environment.

According to Phillips [4] and Tsoutsos et al. [5], the major indirect environmental effects

53 of solar energy comparing with fossil fuels energy consumption that are considered positive are

54 reduced emissions of greenhouse gases, reduced transmission lines from electricity grids,

55 reclamation of degraded land, and improved quality of water resources, among others. In addition,

56 the environmental impacts of PV cell production can also be reduced by converting to more

57 advanced production process [6]. These effects have resulted in increased interest in USSE

58 installations, with many pending permits for installations planned for the future. As more of these

59 plants appear on the landscape, a major challenge is to understand the effects on land use and

60 changes in surface characteristics of the land. These effects depend on the size, type, and location

61 of the installations [4,5], and must be addressed appropriately in energy policies.

62 During the last decade, many researchers have investigated environmental and human

63 effects of solar energy installations, including on biodiversity, visual impacts relating to the loss

64 of amenities as well as visual intrusion from an aesthetic viewpoint, land use, soil, water

65 resources, human health, fragmentation, and changes in the microclimate. In a study on the

66 positive and negative effects of USSE development on biodiversity, soils, water resources, and

67 human health, Hernandez et al. [2] showed that potential effects on the land-cover by USSE

68 plants are relatively small compared to other energy systems. In a general overview of some

69 environmental effects by solar technology, Tsoutsos et al. [5] graded the potentially negative 
70 effects, such as visual impacts, the routine and accidental release of chemicals, land-use, and

71 work safety and hygiene as well as the effect on the ecosystem and on water resources. They

72 suggested that the potential environmental burdens of solar installations depend on the size and

73 nature of the project, and often are site-specific. They associated most of these burdens with the

74 loss of amenities, such as visual impacts or noise in the case of central systems. Klein and Rubin

75 [7] indicated life-cycle greenhouse gas emissions of using thermal energy storage is 4-9 times

76 less than using natural gas-fired energy backup system at a CSP technology plant.

77 Furthermore, Turney and Fthenakis [8] compared the intensity of land use for life-cycles

78 of PV power from the installation and operation of USSE plants with that for coal power. Using

79 two kinds of metrics, transformation and occupation, they found that as the age of the power

80 plant increased, the land-use intensity of PV power became significantly smaller than that for a

81 coal power plant. Horner and Clark [9] used harmonization process to provide a standard method

82 to calculate solar land-use energy intensity by reducing, characterizing and explicating of it for

83 PV and CSP technologies. Murphy et al. [10] showed the off-site land-use energy intensity is

84 less than $1 \%$ of the on-site land-use for PV and CSP technology. In order to assess the

85 environmental and human effects of USSE plants, Phillips [4] applied a mathematical model of

86 sustainability to the results of Turney and Fthenakis [8]; results indicated that installation and

87 operation phases of utility-scale PV solar plants could be considered as sustainable at a strong

88 level.

89 Results of research by Hernandez et al. [11] on land-use efficiency of USSE installations

90 in California indicated that allocated land was used more for PV schemes (85\%) than for CSP

91 (15\%). In addition, PV installations were in greater abundance than CSP installations; however,

92 the type of technology used had no effects on land-use efficiency $\left(\mathrm{Wm}^{-2}\right)$. On the other hand, 
93 land-use efficiency on private land was greater than that on public land. To sum up,

94 environmental and human effects of USSEs, both for PV and CSP installations, depended on the

95 size and nature of the project, and were relatively small compared to other energy systems,

96 especially coal power.

97 USSE plants have an effect on fragmentation of the countryside as well. This effect, in

98 the case of an installation on the ground, refers to the potential loss of the identity elements

99 typical of the region (e.g., cultivability). According to Chiabrando et al. [12], “...fragmentation

100 is often seen as a negative factor and is opposed to nature conservation, as it is in the case of

101 natural areas, since it causes a decrease of the biodiversity." USSE plants also have an effect on

102 microclimates. With PV systems, this happens due to the temperature that is reached by the PV

103 panels during operation as a result of heating caused by sunlight. The temperature of the panels

104 can increase up to $70^{\circ} \mathrm{C}$, which can cause changes by heating the air surrounding the plant.

105 Armstrong et al. [13] studied the effects of solar energy generation technologies on

106 microclimatic changes and consequently on ecosystem carbon cycling and greenhouse gas

107 emissions.

108 USSE plants occupy many square kilometers of desert area, thus affecting the thermal

109 balance, which, according to Gunerhan et al. [14], "may destroy some species living in this kind

110 of harsh environment." This effect could play a big part in choosing the type and location of a

111 solar power plant. Hernandez et al. [15] examined land, energy and environmental compatibility

112 for PV and CSP technology in California and they identified diverse sites for small and utility-

113 scale solar energy that could meet the state energy demand three to five times over. De Marco et

114 al. [16] identified suitable areas for USSE with respect to the analysis of the legislation. They

115 examined the effects of existing solar installation on $\mathrm{CO}_{2}$ sequestration and on avoided $\mathrm{CO}_{2}$. 
116 Beylot et al. [17] compared the environmental effects of utility-scale PV installations that were

117 grid-connected and ground-mounted, using four scenarios for life-cycle assessment (LCA). They

118 found that dual-axis trackers have more of an effect on ecosystem quality than other types, and

119 this was influenced mainly by land occupation. In fact, they found that power plants with dual-

120 axis trackers needed more space between each element of the PV field because that would

121 provide wider shade than fixed and single-axis trackers. In 2014, Qian studied the impact of

122 land-use and land-cover change as a factor of changing in the regional surface energy balance on

123 changes in surface solar radiation [18]. Their study was conducted in eastern China from 1979-

1242008 based on diurnal temperature range in various stations. They reported the reduction in

125 surface solar radiation at most stations due to land-use and land-cover change.

126 The thermal balance of an area can be assessed by remote sensing methods. Over the last

127 few decades, many remote sensing applications have been developed to assess changes in land

128 cover, land use and also potential areas for solar plant installation. Chen et al. [19] provided a

129 statistical example on vegetation estimation, based on multivariate statistical modeling and using

130 remote sensing data. They selected the reflectance of data from four bands of a Huan Jing (HJ-1)

131 charged-coupled device, six vegetation indexes, three principal components from principal

132 component analysis (PCA), and three variables from tasseled-cap transformation to correlate with

133 measured vegetation coverage. According to the results, this method had relatively high precision

134 with environments having various densities of vegetation. Mahtta et al., [20] mapped potential

135 areas for solar plant installation (CSP and PV) using remote sensing techniques considering land

136 slope and solar radiation in India. Calvert et al., [21] reviewed the status of the application of

137 geographic information science and remote sensing techniques to decrease the uncertainties about

138 renewable energy development. 
140 categories. One useful technique for estimating the proportion of each pixel that is covered by a

141 series of known cover types is by spectral mixture analysis (SMA). Lu and Weng [22] applied an

142 SMA approach to solve the mixture problem with low-resolution data, and provided better

143 classification results than traditional maximum-likelihood classifiers. To estimate impervious

144 surfaces, Wang et al. [23] compared the performance of four methods by using linear SMA for 145 spectral-data treatment in the central area of Shanghai, China. Regarding endmember extraction

146 for SMA, Mei et al. [24] proposed an algorithm to integrate spectral similarities and spatial

147 context. Similarly, Plaza et al. [25] presented an automated method for unsupervised

148 determination of pixel purity from multi-dimensional datasets. Song [26] used Bayesian SMA to

149 determine the effects of endmember variability on the estimation of sub-pixel vegetation 150 fractions.

151 The provided review of literature showed remote sensing methods can be used to assess

152 land-cover changes due to USSE construction. Fragmentation of the countryside as well as

153 changes to microclimates and the thermal balance are some negative effects from USSE plants

154 that could lead to changes in the land cover. Moreover, it is widely accepted that almost all kinds 155 of vegetation are sensitive to thermal change. Thus, due to the lack of literature concerning long156 term effects of USSE plants on land-cover changes, this research focuses on the effects of USSE 157 generation facilities on land-cover trends, using remote sensing data. Specifically, the effects on 158 land cover by two USSE installations in an arid environment is examined, Nevada Solar One and 159 the Nellis Solar Power Plant, both installed in southern Nevada within the last decade. This study 160 measured the long-term effects using changes in the land-cover surroundings and within the 161 facility. To understand effects of solar-facility construction on this type of environment, changes 
162 in land-cover trends were classified as pre-installation and post-installation of the plants, based

163 on changes in high-albedo, low-albedo, vegetation, and shadow fractions. The significance of

164 this research is analysis of long-term effects of USSE plants on land cover using remote sensing

165 techniques. These effects are analyzed inside and outside the plant areas.

166 The paper is organized as follows. In section 1, the present state of literature is reviewed.

167 Section 2 describes the study areas and is followed by section 3, which explains the remote

168 sensing data requirements. Methodology is described in section 4. Results and discussions are

169 given in section 5 and is followed by the summary and conclusion in section 6.

170

171 2. Study Area

172 Nevada Solar One and Nellis Solar Power Plant were selected for this study because of their

173 location and solar energy techniques; one plant is located inside an urban area (Nevada Solar

174 One) and the other is located outside the urban area (Nellis Solar Power Plant). In addition, one

175 uses PV techniques (Nellis Solar Power Plant) and the other uses CSP techniques (Nevada Solar

176 One). This study of two types of power plants demonstrates approach and methodology while

177 identifying their effect on land cover.

$179 \quad 2.1$ Nevada Solar One

180 Nevada Solar One (NS-1) is a concentrated solar power plant with a footprint of $1.62 \mathrm{~km}^{2}$ in the

181 Eldorado Valley near Boulder City, Nevada. The effect on land cover is studied over a

182 rectangular area $\sim 127 \mathrm{~km}^{2}$ around the facility. It has been built within the City's Energy Resource

183 Zone, which requires renewable generation as part of plant development permits. This plant uses

184 parabolic concentrators with mirrors to focus the sun's energy onto oil-carrying receiver tubes.

185 The heated oil is used to boil water into steam in order to drive a turbine power generator. This 
186 plant uses proprietary technology to track the sun's location and to concentrate rays during peak

187 demand hours. The solar plant provides mixed power, using 98\% concentrated solar and 2\%

188 natural gas. Electricity production is more than 130 gigawatt hours per year [27]. NS-1

189 construction began in February 2006, and operations started in June 2007.

Figure 1 compares two aerial images of NS-1 both during construction in 2006 (Fig. 1a)

191 and after completion in 2010 (Fig. 1b). In Figure 1a, the land for the upper plant section has been

192 prepared for the construction in 2006. In Figure 1b, the solar panels have been installed in the

193 upper section and panels in the lower section are getting installed in 2010. In order to investigate

194 changes in land-cover characteristics further, Points 1A and 2A were selected for further analysis

195 and comparison using the proposed methods. Point $1 \mathrm{~A}$ is located within the facility areas and

196 Point $2 \mathrm{~A}$ is located outside of the facility.
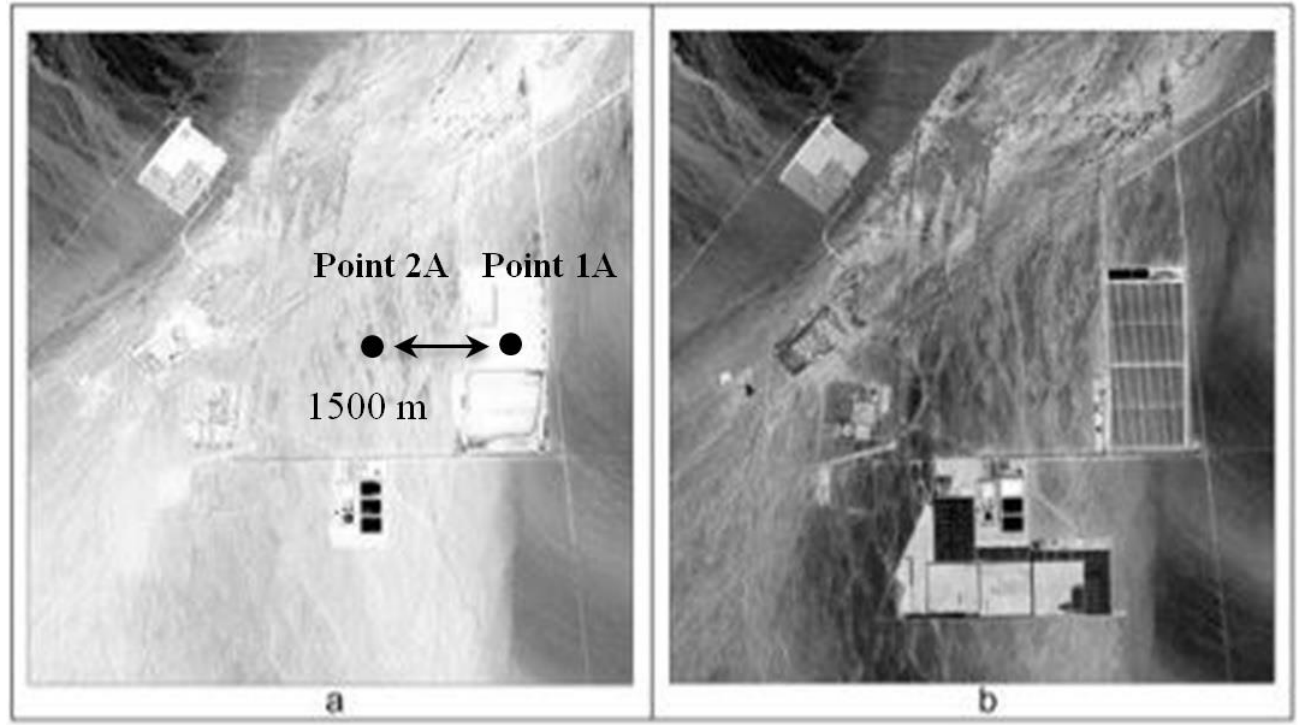

Figure 1. Nevada Solar One in a) 2006 and b) 2010.

\subsection{Nellis Solar Power Plant}

201 Nellis Solar Power Plant (NSPP), a photovoltaic power plant, spreads over $0.57 \mathrm{~km}^{2}$ within

202 Nellis Air Force Base located in northeast of Las Vegas in Clark County, Nevada. The effect on 
203 land cover is studied over a rectangular area $\sim 7.76 \mathrm{~km}^{2}$ around the facility. PV cells generate

204 electrical power by converting sunlight into direct current electricity. The system contains

205 approximately 70,000 PV panels that employ an advanced single-axis sun-tracking system.

206 NSPP generates more than 25 gigawatt hours of electricity annually, and supplies more than $25 \%$

207 of the power at the Nellis Air Force Base [28].

208 NSPP construction began in April 2007, and operations started in October 2007. Figure 2

209 compares two aerial images of NSPP, including before construction in 2006 and after completion

210 in 2010. In Figure 2a, the land has been prepared for the construction in 2006. Figure 2-b shows

211 the solar panels completely installed in 2010. Similar to NS-1, in order to further investigate the

212 changes in land-cover characteristics, Points 1B and 2B were selected for further analysis using

213 the proposed methods. Point 1B is located within the facility area and Point 2B is located outside

214 of the facility.

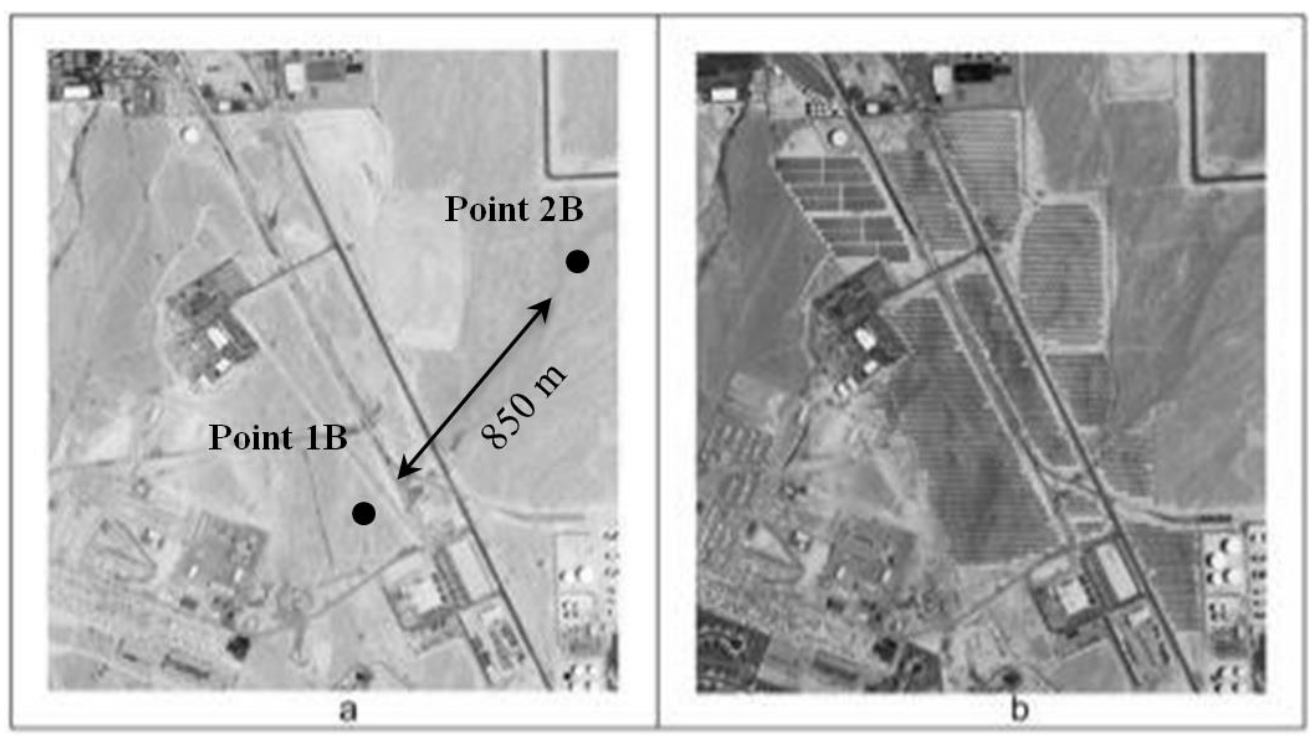

Figure 2. Nellis Solar Power Plant in a) 2006 and b) 2010. 


\section{3. Remote Sensing Data}

219 This research used aerial imagery from the Landsat 5 thematic mapper (TM) as well as from the

220 National Agriculture Imagery Program (NAIP). TM imagery from Landsat 5 was used to

221 estimate land-cover changes, and the higher resolution NAIP imagery was used to validate the 222 results.

\subsection{Data from Landsat 5 Thematic Mapper}

225 Landsat 5 is a low-earth-orbit satellite, recognized as the longest operating mission in history for 226 an Earth-observing satellite. Its payload includes the thematic mapper instrument, which has

227 orbited the planet more than 150,000 times and has transmitted over 2.5 million images. TM

228 images consist of seven spectral bands, including visible, near-infrared, thermal, and mid-

229 infrared bands. Bands 1, 2 and 3 are visible, Bands 4 and 5 are near-infrared, Band 6 is thermal,

230 and Band 7 is mid-infrared. Available since 1984, this multi-channel data is used extensively to

231 differentiate land-cover types and study trends [29-31]. This long-term data provides an

232 opportunity to perform time-series analyses in order to understand the effects of large-scale solar 233 power plants.

234 Standard TM data products are available as digital numbers (DN), which are converted to

235 spectral radiance at the sensor's aperture, using the following equation [32]:

$$
L_{\lambda}=\left(\frac{L M A X_{\lambda}-L_{\text {calmax }}-Q_{\text {calmin }}}{Q_{\lambda}}\right)\left(Q_{\text {cal }}-Q_{\text {calmin }}\right)+\operatorname{LMIN}_{\lambda}
$$

236 Where:

$237 L_{\lambda}=$ Spectral radiance at the sensor's aperture $[\mathrm{W} /(\mathrm{m} 2 \mathrm{sr} \mu \mathrm{m})]$

$238 Q_{c a l}=$ Quantized calibrated pixel value $[\mathrm{DN}]$

$239 Q_{\text {calmin }}=$ Minimum quantized calibrated pixel value corresponding to $L M I N_{\lambda}[\mathrm{DN}]$ 
$240 Q_{\text {calmax }}=$ Maximum quantized calibrated pixel value corresponding to $L M A X_{\lambda}[\mathrm{DN}]$

$241 L M I N_{\lambda}=$ Spectral at-sensor radiance that is scaled to $Q_{\text {calmin }}\left[\mathrm{W} /\left(\mathrm{m}^{2} \mathrm{sr} \mu \mathrm{m}\right)\right]$

$242 L M A X_{\lambda}=$ Spectral at-sensor radiance that is scaled to $Q_{\text {calmax }}\left[\mathrm{W} /\left(\mathrm{m}^{2} \mathrm{sr} \mu \mathrm{m}\right)\right]$

243 Spectral radiance data can be converted to surface reflectance $(\rho)$ data to reduce scene-to-scene

244 variability. Chander et al. [32] provided an equation to convert the spectral radiance at the

245 sensor's aperture to the top-of-atmosphere (TOA) reflectance of the Earth.

246 Recently, the U.S. Geological Survey (USGS) has released climate data records (CDR),

247 which provides surface reflectance data of TM. Because this current research began before the

248 release of the CDR data, however, spectral radiance images were calculated from DN images. In

249 this research, spectral radiance images were used to estimate land-cover change. Pure pixels

250 were selected from the same images for the SMA process, and were validated based on a high-

251 resolution image. After the normalization process, which will be described in methodology

252 section, spectral radiance images and surface reflectance images were identical.

253 Both study sites were covered by Landsat TM scenario for Path 39 and Row 35. From

254 March 2004 to February 2011, 114 images were acquired from the USGS Earth Resource

255 Observation Systems (EROS) Data Center (EDC). These images were analyzed visually in order

256 to isolate 76 cloud-free images appropriate for further processing. All bands had a spatial

257 resolution of $30 \mathrm{~m}$, except for thermal infrared, which was $120 \mathrm{~m}$. Thermal infrared was not used

258 during data processing.

$260 \quad$ 3.2 Data from the National Agriculture Imagery Program

261 The National Agriculture Imagery Program acquires aerial imagery during the agricultural

262 growing seasons in the continental U.S. [33], at 1-m resolution. The frequency bands that are 
263 available are natural colors - red, green, and blue (RGB). However, beginning in 2007, some

264 states have been delivering four bands of data, RGB as well as near infrared. In this research,

265 NAIP imagery acquired during May 2010 was used for verification of the results. This imagery

266 was obtained from the website for W.M. Keck Earth Science \& Mining Research, from which

267 data from 2006, 2009, 2010, and 2013 were available (http://keck.library.unr.edu/) [34].

268

269 4. Methodology

270 Data processing and analysis primarily consisted of 1) a data treatment step to reduce the

271 dimensions of the Landsat imagery, 2) data unmixing in order to retrieve information of sub-

272 pixel land-cover, and 3) trend analysis to estimate changes in the land-cover. Figure 3 shows the

273 flowchart of these applied methods.

274

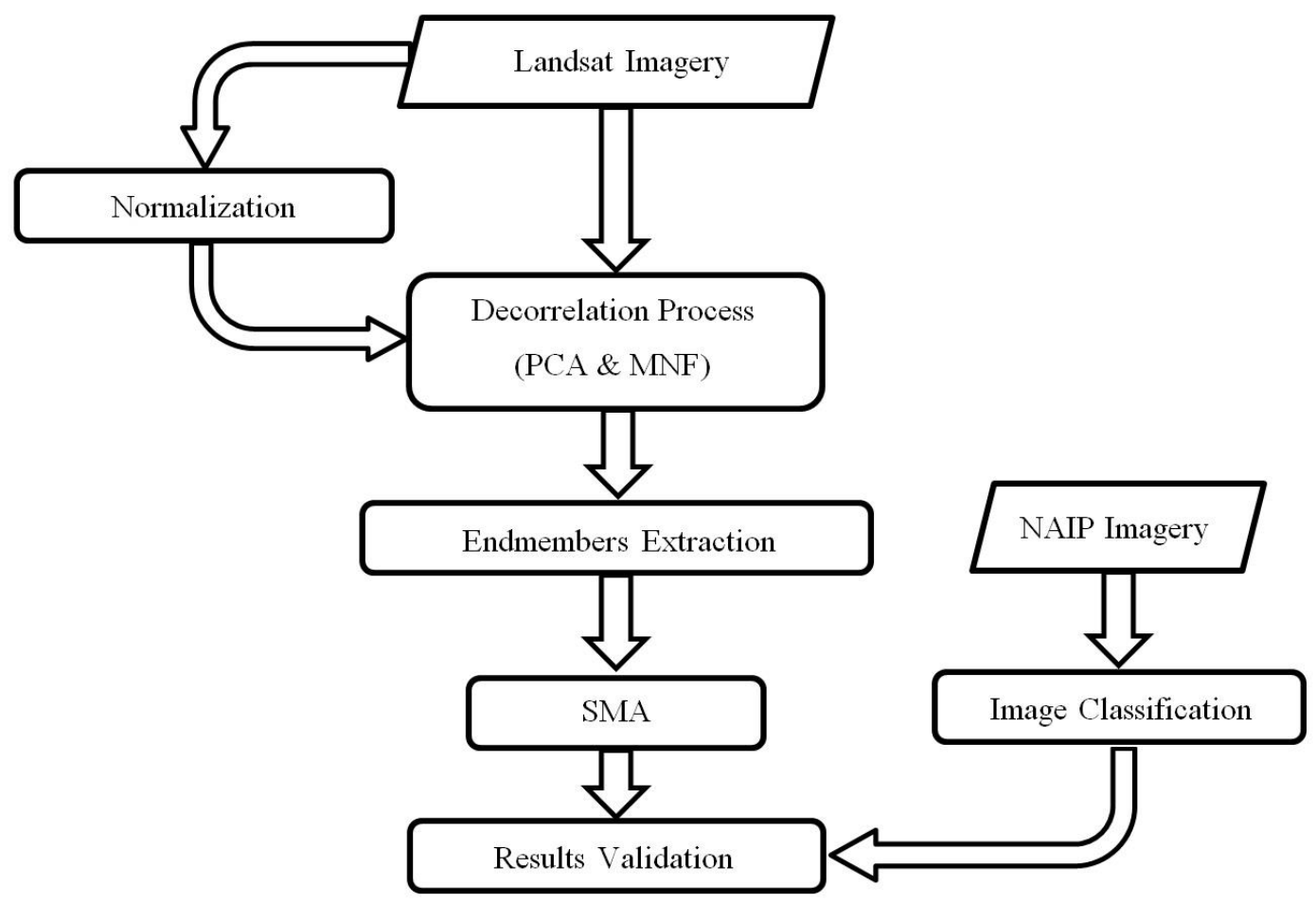

276 Figure 3. Flowchart of the methods used for data treatment of the Landsat 5 imagery. 


\subsection{Data Treatment Techniques}

278 In order to convert correlated Landsat 5 TM imagery bands into a set of linearly uncorrelated

279 variables, two methods were applied that include both principal component analysis (PCA)

$280[35,36]$ and minimum noise fraction (MNF) [37]. These methods basically involve a constrained

281 rotation of data in a multi-dimensional space. In PCA, variance represents the information, and

282 the data rotation is performed such that variance is maximized along fewer dimensions. The data

283 projections along these dimensions are called principal components. Similarly, the MNF rotates

284 the data to achieve minimum noise along fewer dimensions. The data projections along these

285 dimensions are called minimum noise components. Both PCA and MNF transform Landsat 5

286 TM imagery such that the information of the transformed imagery is concentrated into fewer

287 bands. These transforms are tested over arid regions to identify the most applicable methods for 288 land-cover analysis of solar facilities.

289 The PCA and MNF transforms were used with both original data and normalized data.

290 For original data, spectral radiance images are the input without any change; normalized data, on

291 the other hand, is converted to get the zero mean (zero-centering) and the unit variance

292 (normalization) for each band. The terms 'original' and 'normalized' are used to identify the

293 results of these two input data variations. The PCA and MNF transforms were implemented

294 using MATLAB R2014a. MNF had the lowest noise fraction in the last component, whereas

295 PCA had the largest variance in the first component. In this research, a TM cloud-free image,

296 acquired on July 18, 2007, had been selected to find endmembers using PCA and MNF

297 components. Thus, PCA and MNF techniques both were applied to the image. Table 1 lists the

298 percentage of the total variance explained by each principal component in the PCA bands, and

299 the noise fraction of each MNF band. 
Table 1. PCA Band Variances and MNF Bands Noise Fractions

\begin{tabular}{|c|c|c|c|c|c|c|}
\hline \multirow{2}{*}{$\begin{array}{c}\text { Band } \\
\text { Number }\end{array}$} & \multicolumn{2}{|c|}{ PCA-Original } & \multicolumn{2}{c|}{ PCA-Normalized } & $\begin{array}{c}\text { MNF- } \\
\text { Original }\end{array}$ & $\begin{array}{c}\text { MNF- } \\
\text { Normalized }\end{array}$ \\
\cline { 2 - 7 } & $\begin{array}{c}\text { Total } \\
(\%)\end{array}$ & Eigance & $\begin{array}{c}\text { Total } \\
\text { Variance } \\
(\%)\end{array}$ & Eigenvalues & $\begin{array}{c}\text { Noise } \\
\text { Fraction }\end{array}$ & $\begin{array}{c}\text { Noise } \\
\text { Fraction }\end{array}$ \\
\hline Band 1 & 94.3341 & 1444.5980 & 89.8667 & 5.3920 & 0.8271 & 0.1168 \\
\hline Band 2 & 4.1613 & 63.7245 & 7.4157 & 0.4449 & 0.2522 & 0.0798 \\
\hline Band 3 & 1.1043 & 16.9105 & 1.7782 & 0.1067 & 0.1891 & 0.0694 \\
\hline Band 4 & 0.2154 & 3.2986 & 0.5798 & 0.0348 & 0.1169 & 0.0434 \\
\hline Band 5 & 0.1796 & 2.7505 & 0.2406 & 0.0144 & 0.0828 & 0.0390 \\
\hline Band 6 & 0.0053 & 0.0814 & 0.1188 & 0.0071 & 0.0446 & 0.0326 \\
\hline
\end{tabular}

The first three components of PCA-Original and PCA-Normalized covered $99.6 \%$ and

$99.06 \%$ of the variance, respectively; the last three components of MNF-Original and MNF-

Normalized carried $24.4 \%$ and $11.5 \%$ of the noise, respectively.

The transformation of TM imagery into fewer bands for most of the information can be used continuously in further analysis, such as for target identification, image classification, and subpixel retrieval. Often, pure pixels (containing a single land cover called an endmember) exhibit extreme values in these bands, whereas mixels (pixels containing multiple endmembers)

310 exhibit intermediate values, depending on the level of mixing. As shown in Figures 4 and 5, the

311 PCA and MNF components were graphed as scatter plots to identify the endmembers identified

312 as extreme corners (vertices) in these plots [25,38] (Boardman 1994; Plaza et al. 2002). Figure 4

313 shows the 2-D scatter plot of PCA-Original- and -Normalized datasets and Figure 5 shows the 2-

314 D scatter plot for MNF-Original and -Normalized datasets. The types of the pixels at the extreme

315 vertices in the scatter-plots were determined by linking the pixels back to the image-feature 316 space. 

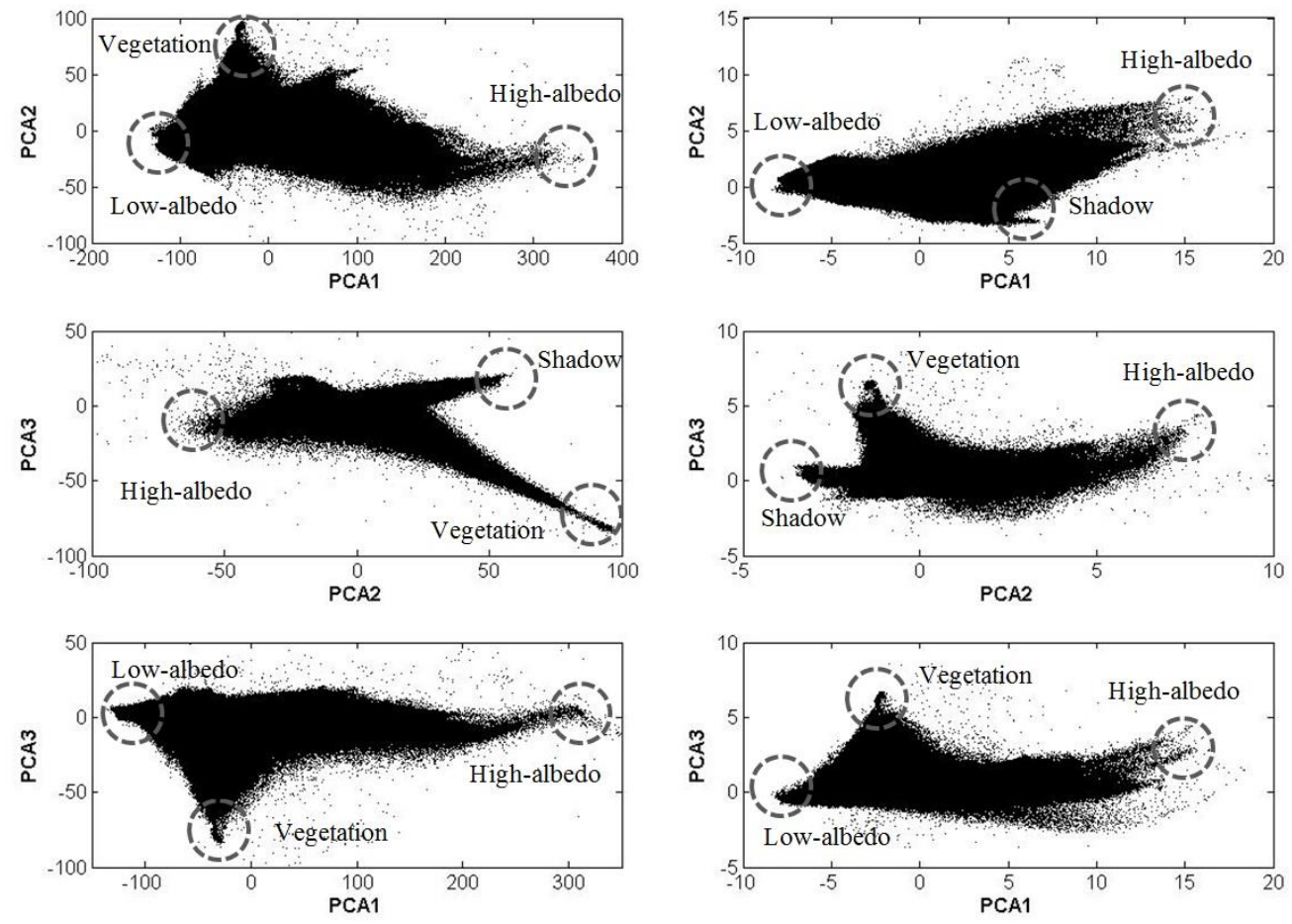

Original

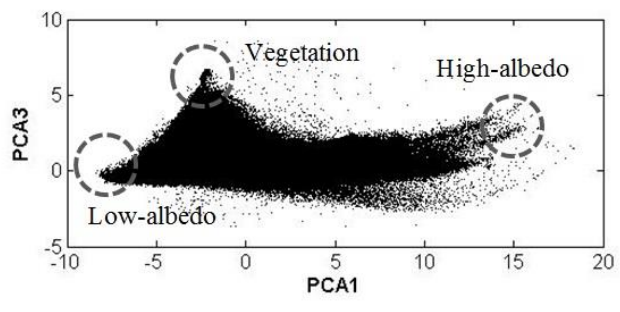

Normalized

318 Figure 4. 2-D scatterplot of the first three principal components of PCA (July 18, 2007).
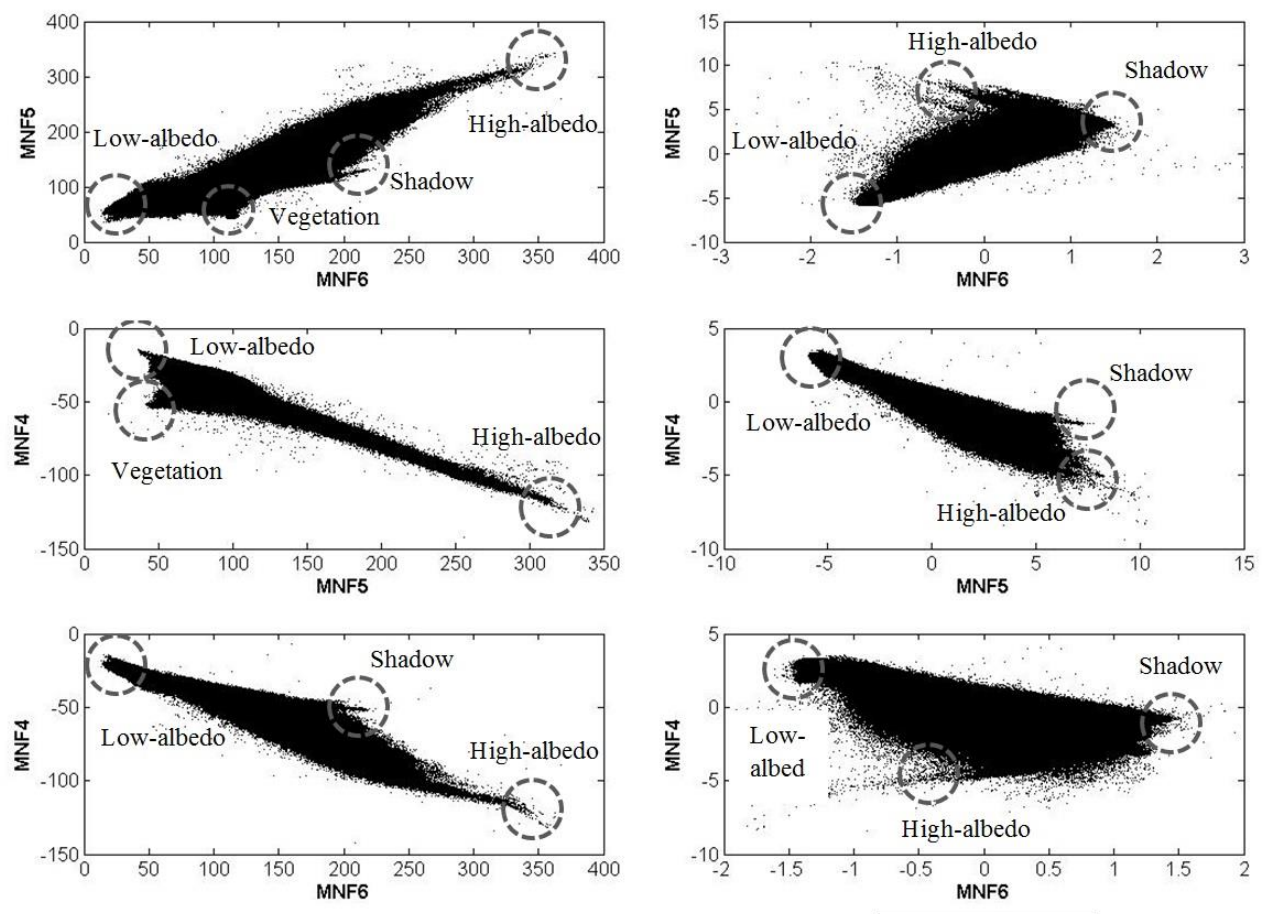

Original

Normalized

320 Figure 5. 2-D scatterplot of the last three principal components of MNF (July 18, 2007). 
323 vegetation (VG), and shadow ( $\mathrm{SH})$. High albedo represents land covers that reflect most of the

324 light, such as concrete roofs and sand. Low albedo is associated with land covers that absorb

325 most of the light and appear relatively dark colored to the eyes, such as asphalt and water bodies.

326 For each endmember type, at least 20 representative pixels were selected. Thus, spectral

327 signatures of $\mathrm{HA}, \mathrm{LA}, \mathrm{VG}$, and $\mathrm{SH}$ land-cover types were extracted using four variations of data

328 treatment, including PCA-Original, PCA-Normalized, MNF-Original, and MNF-Normalized.

329 Spectral signatures of endmembers can be used to retrieve subpixel land cover of mixels

330 by means of a process of unmixing. Several techniques have been developed, including linear

331 spectral unmixing, fuzzy classification, and automatic subpixel detection. In this research,

332 spectral mixture analysis was used to retrieve subpixel land cover.

\section{$334 \quad 4.2 \quad$ Spectral Mixture Analysis}

335 Often, a pixel contains a mixture of land-cover categories. In fact, the number of pure pixels that

336 contain only one feature or class is small. Nevertheless, the value of a pixel with a mixed land

337 cover depends on the ensemble of responses for each constituent land-cover. SMA has been

338 extensively employed for land-cover mapping using TM data [26,39,40]. This technique seeks to

339 determine the likely composition of constituent land-cover types or endmembers to produce the

340 measured pixel value,

$$
b^{i}=f_{1}^{i} \cdot \rho_{1}^{i}+f_{2}^{i} \cdot \rho_{2}^{i}+\cdots+f_{N}^{i} \cdot \rho_{N}^{i}+e,
$$


342 where $b^{i}$ is measured $i^{\text {th }}$ band spectral radiance of a pixel with $N$ endmembers. The $\rho^{i}$ and $f^{i}$ are

343 spectral reflectance and subpixel aerial fraction of an endmember, respectively; and $e$ is the

344 residual error. Such relationships for an imagery with $K$ bands result in a system of equations

345 that can be written in matrix form as

$$
\mathbf{b}=\overline{\bar{\rho}} \boldsymbol{f}+\boldsymbol{e}
$$

347 where $\overline{\overline{\boldsymbol{\rho}}}$ is a $K$ by $N$ matrix with rows corresponding to $K$ bands and columns corresponding to $N$ 348 endmembers. The symbols $\boldsymbol{f}$ and $\boldsymbol{e}$ are column vectors of subpixel aerial fraction of endmembers 349 and the residual errors, respectively. The SMA approach poses two conditions on the subpixel 350 land-cover fractions given by:

$$
\sum_{n=1}^{N} f_{n}=1
$$

352 and

$$
0 \leq f_{n} \leq 1, n=1,2, \ldots, N
$$

354 Equations (3), (4), and (5) were solved for each cell to estimate fractions such that residual error $355 R$ is minimized [41]. The Nedler-Mead method (available in MATLAB 2014a), used to minimize

356 the residual, is a multidimensional, unconstrained, nonlinear minimization for finding the

357 minimum of a scalar function of several variables [42]. 


\subsection{Validation}

360 For validation, the SMA results were compared with land cover based on high-resolution NAIP

361 imagery. Subpixel fractions were retrieved for a TM image acquired on May 10, 2010, and

362 compared to classification of an NAIP image acquired on May 7, 2010. The comparison was

363 made over a randomly selected rectangular area within the City of Las Vegas. The NAIP image

364 was classified using a supervised image-classification tool in ArcGIS 10.2.2 for the same four

365 endmembers used in SMA. Pixels representing the endmembers were manually selected for the

366 image-classification process. Additionally, land-cover fractions of all TM image pixels were

367 calculated using SMA. As mentioned earlier, NAIP imagery has a 1-m resolution and TM

368 images have a 30-m resolution. Thus, pixels of each TM image included 900 NAIP pixels.

369 Therefore, two land-cover datasets were calculated for the land-cover fractions of the TM images

370 and the NAIP imagery. In order to compare TM image results with NAIP imagery results, four

371 types of data were used as input for the SMA process: PCA-Original, PCA-Normalized, MNF-

372 Original, and MNF-Normalized. The correlation coefficient was calculated to determine the

373 relationship between image classification and SMA results.

\section{$375 \quad 4.4 \quad$ Trend Analysis}

376 In order to analyze the effects of the construction of USSE plants on land-cover patterns, time-

377 series data were classified as pre-installation, syn-installation, and post-installation data. In

378 addition, the average land-cover fraction of each land-cover type was calculated for pre-

379 installation, syn-installation, and post-installation. Because some land covers followed an annual

380 periodic pattern, the averaging method was used to minimize the annual trends effects. 


\section{$382 \quad$ 5. Results and Discussion}

383 In this section, the results of subpixel land-cover estimation and their temporal analysis with

384 respect to solar installations are presented. First, a brief comparison of four data treatments is

385 discussed to identify a suitable treatment for selecting endmembers and applying SMA. Second,

386 the fractional area maps of four endmembers produced by SMA are presented and discussed at

387 the two study sites. Finally, the pre- and post-installation fractional area maps are compared to

388 estimate the effects of solar facilities on land-cover patterns.

\section{$390 \quad 5.1 \quad$ Comparisons of Data Treatment Techniques}

391 In order to identify a suitable treatment for selecting endmembers, the SMA results were

392 validated using NAIP imagery acquired on May 7, 2010. To do so, a random rectangular area

393 was selected within the City of Las Vegas. Figure 6a displays the area on which the validation

394 process was applied. The image in Figure $6 \mathrm{~b}$ was obtained from the image classification process

395 for the four showing classes (in the legend), which were manually determined. Commercial

396 building roofs and high-reflectance soils were classified as high-albedo, and roads and water

397 bodies were classified as low-albedo. Shadow was mainly represented by the shadows of large

398 buildings. As shown in Figure 6b, SMA was applied on the closest available Landsat imagery,

399 acquired on May 10, 2010, in the same area on the first four bands of PCA and the last four

400 bands of MNF, based on the four endmember types obtained from Figures 4 and 5. 


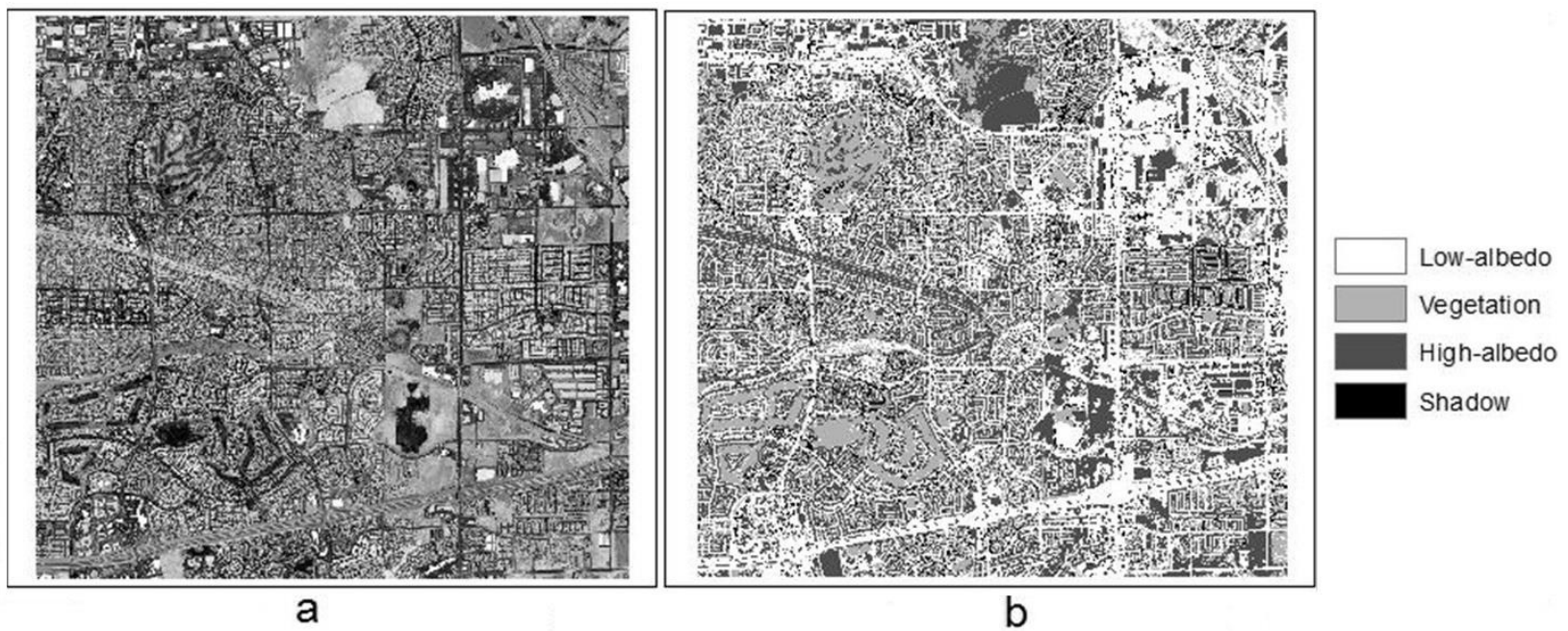

a

b

402 Figure 6. a) NAIP imagery (7 May 2010) of a random area in the City of Las Vegas b) Classified 403 image.

Figure 7 shows the relationship between the estimated fractions of each endmember by

406 SMA and NAIP imagery classifications. According to Figure 7, high-albedo, low-albedo, and

407 vegetation can be estimated with higher correlation coefficient by PCA-Normalized $(r=0.58$ to $r$

$408=0.79)$. In addition, MNF- Original shows the highest correlation coefficient for vegetation $(\mathrm{r}=$

409 0.81). The calculated fractions for shadow have low-correlation coefficients. The possible reason

410 might be that a shadow moves along the ground throughout the day, and the NAIP imagery and

411 the Landsat images were not taken at the same time of day, therefore, the fraction of shadow in

412 the NAIP imagery differs from that of the Landsat images. 


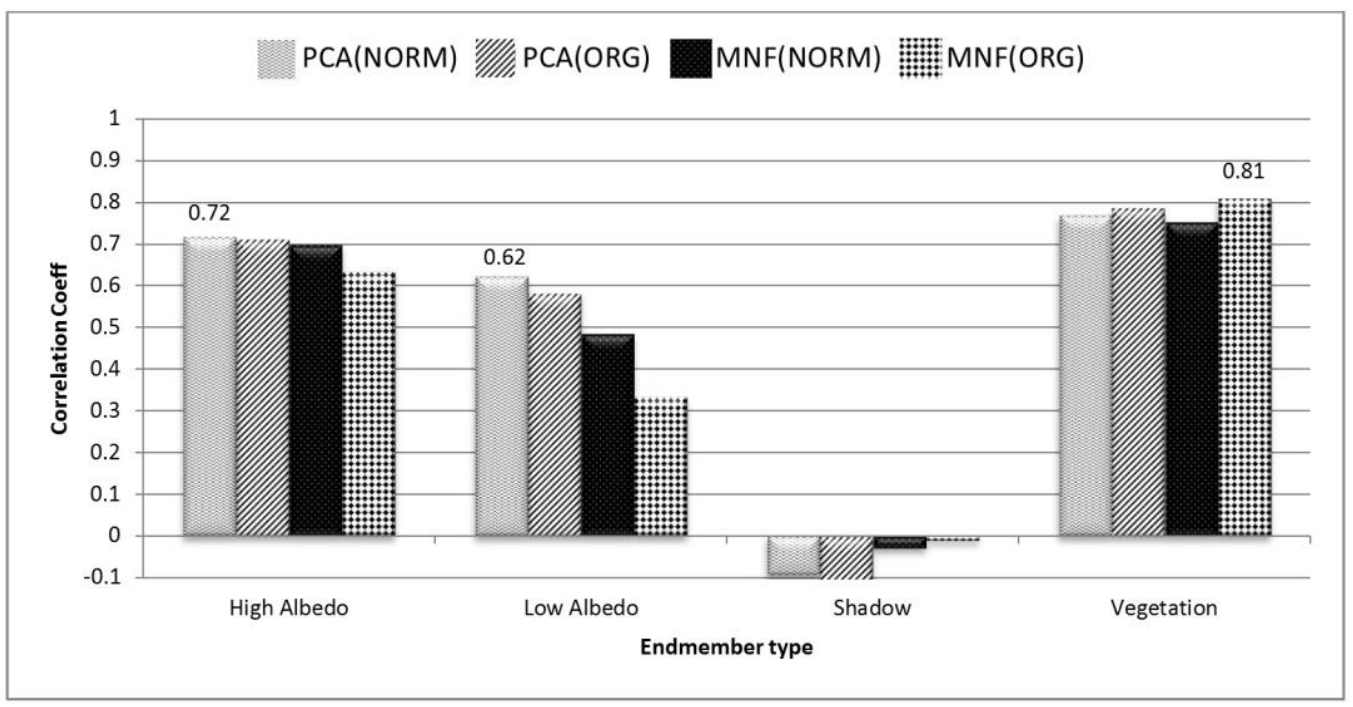

Figure 7. Relationship between the estimated fractions of each endmember by NAIP imagery classification and applied methods (7 May 2010).

418 MNF-Original. The first band of PCA (PCA1) and the last band of MNF (MNF6) clearly

419 represent the endmembers. In contrast, endmember values of PCA's last band (PCA4) and

420 MNF's first band (MNF3) were in the lower range and were relatively hard to recognize.
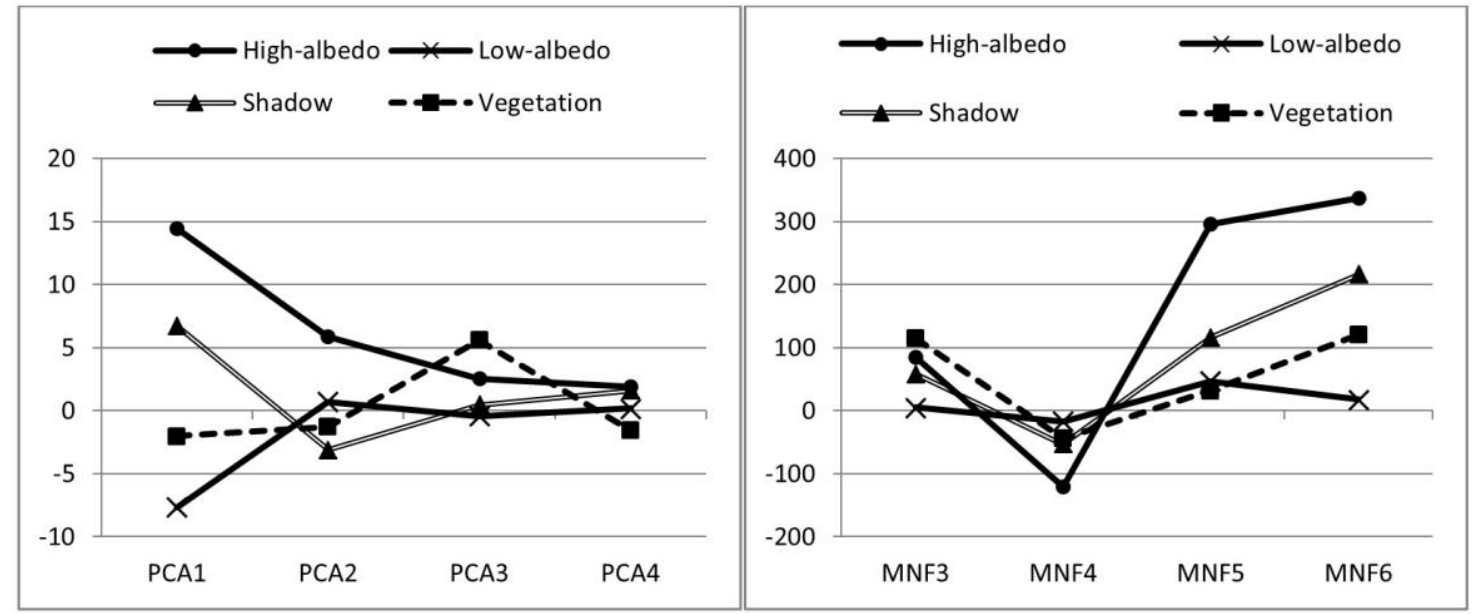

422 Figure 8. Reflectance characteristics of the endmembers for PCA-Normalized and MNF-Original 


\section{$425 \quad 5.2 \quad$ Trend Analysis}

426 According to the correlation coefficients obtained in Figure 7, PCA-Normalized and MNF-

427 Original datasets were selected as the data preparation methods used to apply SMA on Landsat 5

428 TM images from 2004 to 2011. SMA was applied to 76 cloud-free PCA-Normalized and MNF-

429 Original images (Landsat 5 TM). The calculation process was pixel by pixel, and the result of

430 each pixel was independent of the other pixel results.

431 The mathematical process was applied to satisfy Equation (2) with the constraint

432 equations, (3) and (4). Accordingly, the summation of the endmember fractions in each pixel

433 must be equal to 1 ; however, the results showed some errors for certain pixels. One way to

434 determine errors was to find the summation of the four fractions and set the acceptable range as

435 high and low limits for the data. As a result, 1.1 and 0.9 were assumed as the high and low limits,

436 respectively. An unreliable pixel was defined as a pixel with a summation either less than 0.9 or

437 greater than 1.1. Therefore, the ratio of number of unreliable pixels to all pixels was calculated

438 for the two solar plants.

439 Figure 9 shows the percent of error in each area for the two datasets. According to Figure

4409 , the calculated results by PCA-Normalized had less error percentage to compare with MNF-

441 Original. The average percentage error for PCA-Normalized results at Nevada Solar One and the

442 Nellis Solar Power Plant area were 3.09\% and 6.81\%, respectively; the average percentage error

443 for MNF-Original results were $29.09 \%$ and $32.86 \%$, respectively. A possible reason for the

444 lower errors in Nevada Solar One was that this facility was located out of town, and so the pixels

445 were not filled by complicated and mixed endmembers. The Nellis Solar Power Plant is located

446 within a urban area; therefore, pixel structures were more complicated than in the desert. Further, 
447 the results of SMA on PCA-Normalized had a higher number of errors during winter and

448 summer and a lower number of errors in fall and spring; in contrast, the error plot of MNF-

449 Original did not have a specific pattern. Consequently, SMA on PCA-Normalized resulted in the 450 highest accuracy.
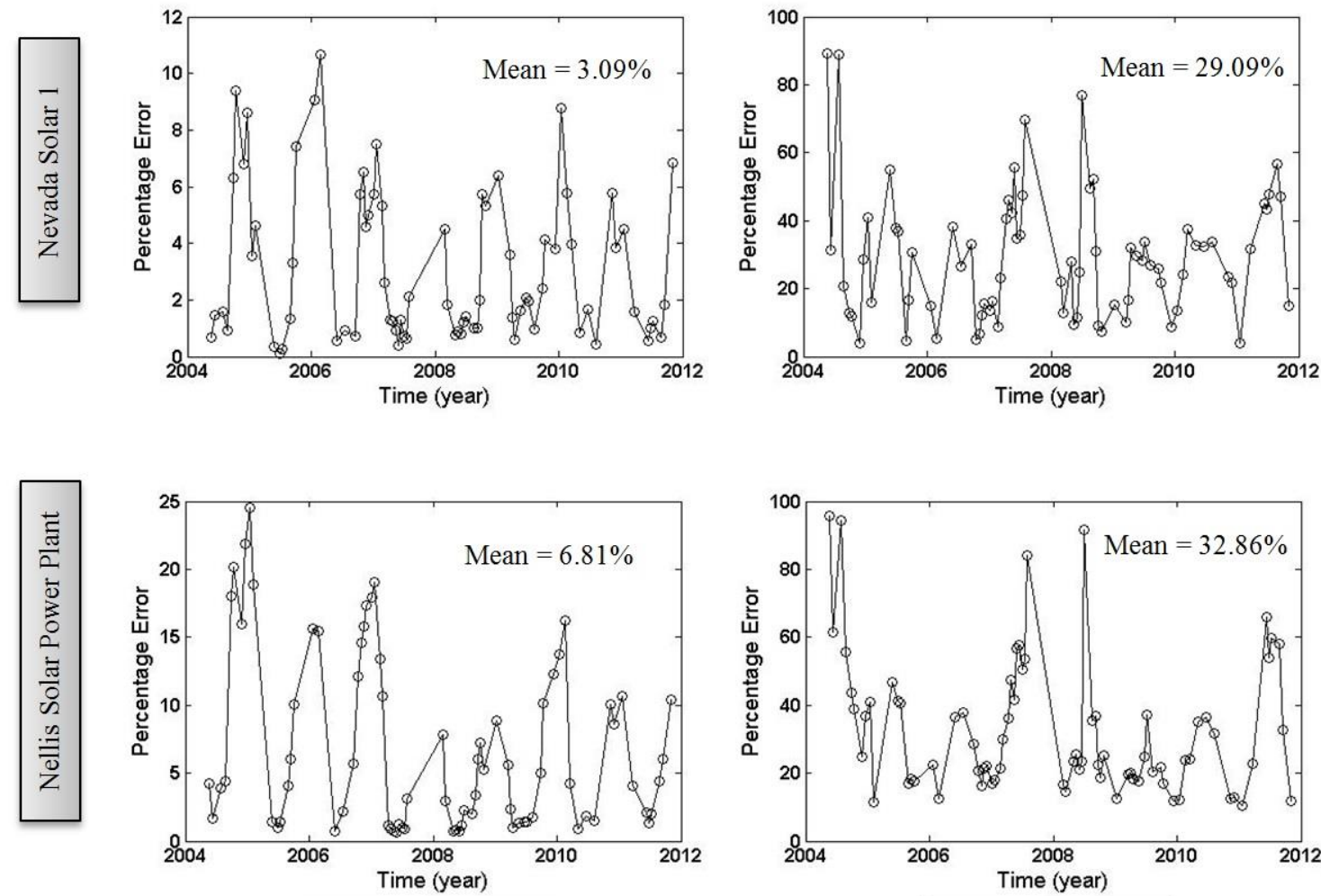

451

PCA-Normalized

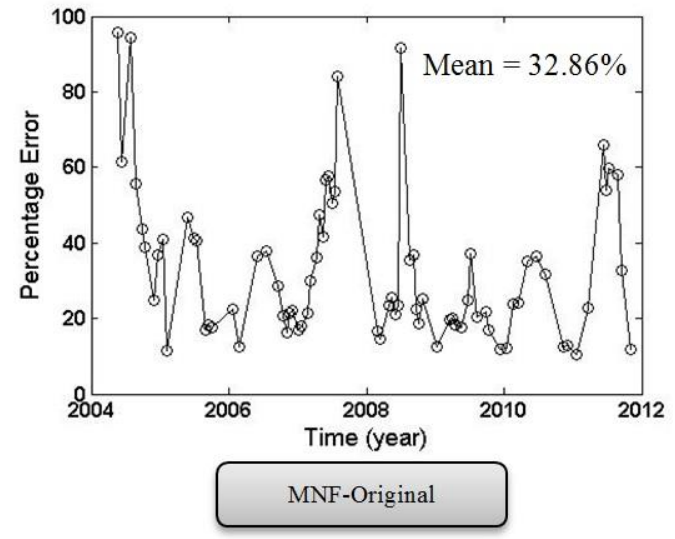

452

Figure 9. Percentage of error in calculated land-cover fractions from 2004 to 2011.

453

The time series of endmember changes, obtained from SMA on PCA-Normalized, were

455 plotted for Points $1 \mathrm{~A}$ and 1B within the two facilities areas (Figures 10 and 12), and Points 2A 456 and 2B for outside of the facilities (Figures 11 and 13). 

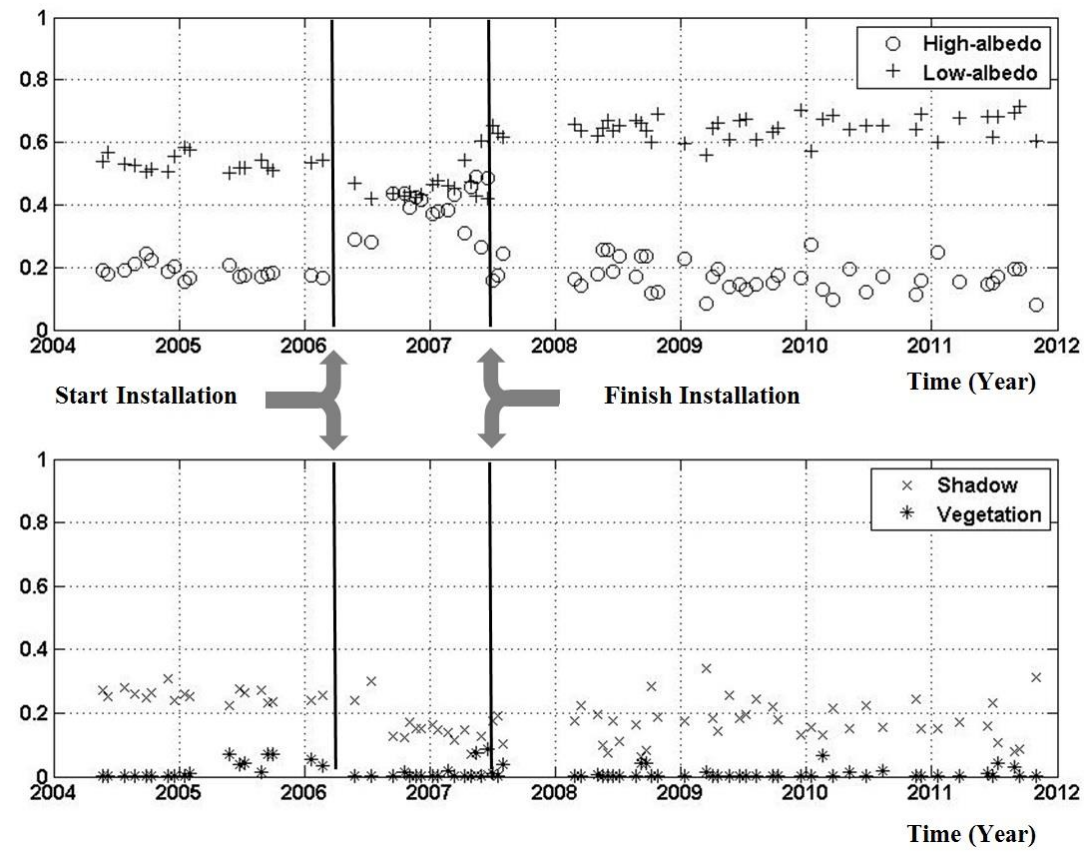

458 Figure 10. Time series of land-cover types at Point 1A, located inside Nevada Solar One.
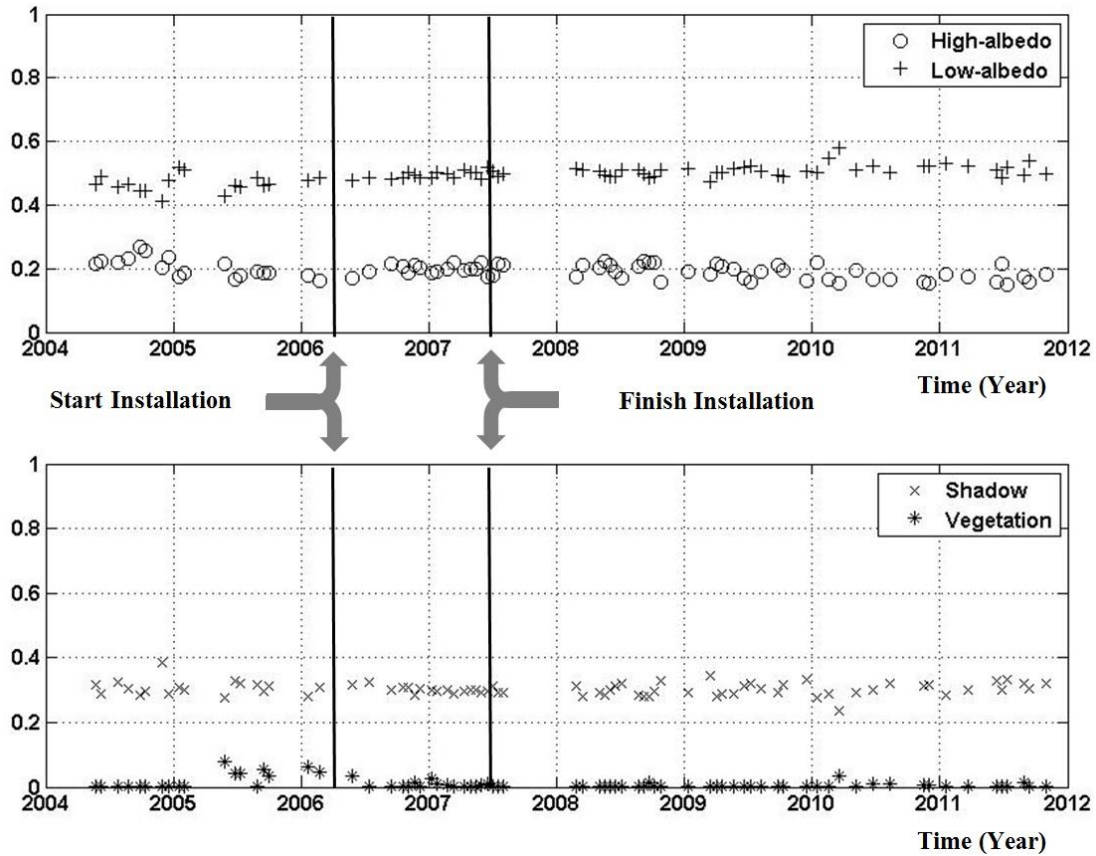

Figure 11. Time series of land-cover types at Point 2A, located outside Nevada Solar One 

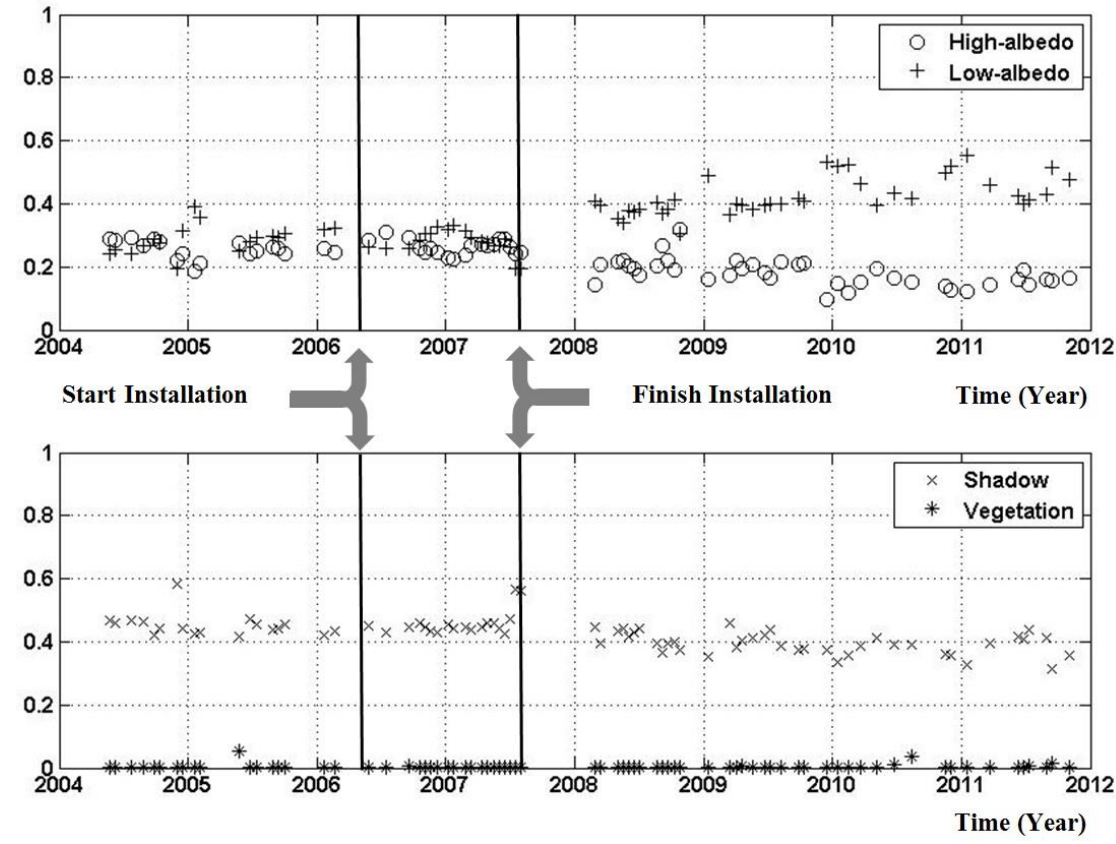

462 Figure 12. Time series of land-cover types at Point 1B, located inside the Nellis Solar Power
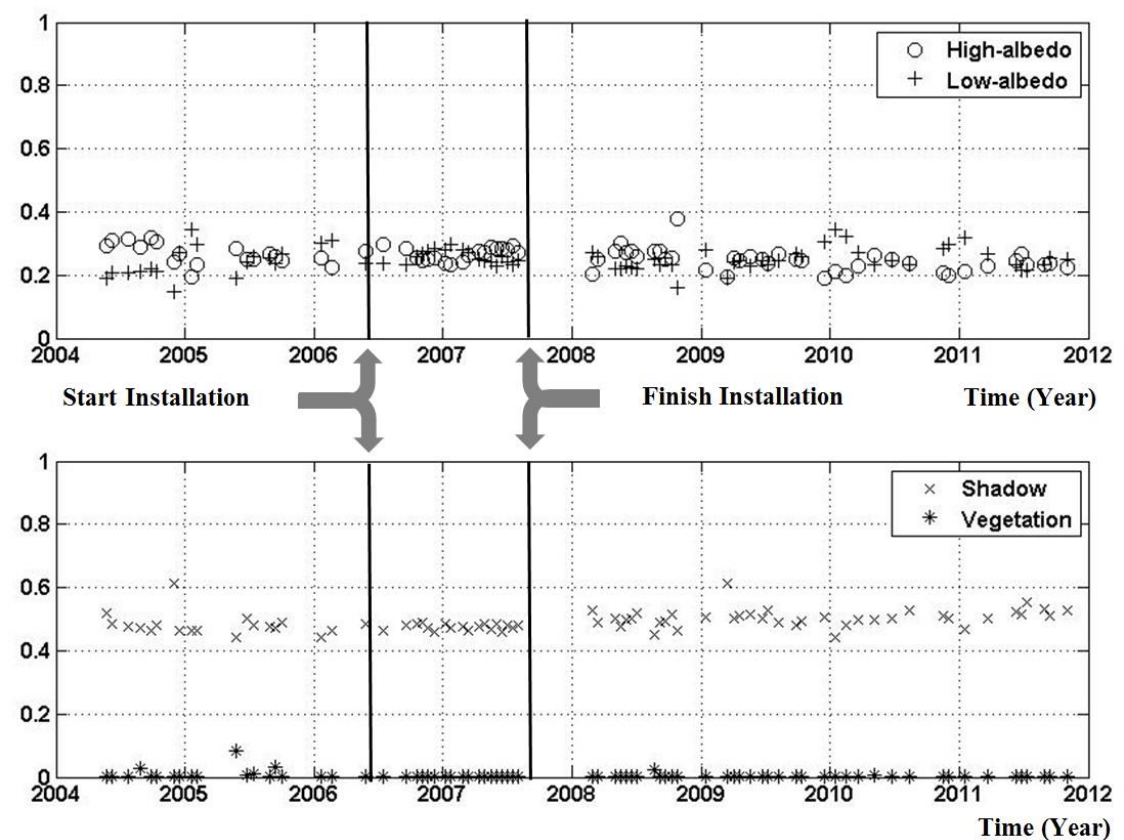

465 Figure 13. Time series of land-cover types at Point 2B, located outside the Nellis Solar Power 
For clarity, high-albedo and low-albedo fractions were plotted separate from vegetation

469

470

471

472

473

474

475

476

477

478

479

480

and shadow fractions. Mean fraction values of endmembers for pre-installation, syn-installation, and post-installation at Points 1A, 2A, 1B, and 2B were calculated (Table 2).

Table 2. Mean values of Endmembers for Pre-installation, Syn-installation, and Post-installation at Points 1A, 2A, 1B, and 2B.

\begin{tabular}{|c|c|c|c|c|}
\hline Point & Endmember & $\begin{array}{c}\text { Pre- } \\
\text { Installation }\end{array}$ & $\begin{array}{c}\text { Syn- } \\
\text { Installation }\end{array}$ & $\begin{array}{c}\text { Post- } \\
\text { Installation }\end{array}$ \\
\hline \multirow{4}{*}{ Point 1A } & HA & 18.47 & 39.18 & 19.13 \\
\cline { 2 - 5 } & LA & 53.01 & 46.05 & 63.12 \\
\cline { 2 - 5 } & SH & 25.98 & 14.77 & 16.38 \\
\cline { 2 - 5 } & VG & 2.53 & 0.001 & 1.36 \\
\hline \multirow{4}{*}{ Point 2A } & HA & 20.31 & 19.6 & 18.53 \\
\cline { 2 - 5 } & LA & 46.5 & 48.84 & 50.77 \\
\cline { 2 - 5 } & SH & 30.46 & 29.47 & 30.42 \\
\cline { 2 - 5 } & VG & 2.73 & 2.08 & 0.27 \\
\cline { 2 - 5 } & HA & 28.58 & 28.99 & 18.19 \\
\cline { 2 - 5 } & LA & 26.37 & 26.05 & 42.3 \\
\cline { 2 - 5 } & SH & 44.91 & 44.84 & 39.43 \\
\hline \multirow{4}{*}{ Point 2B } & VG & 0.14 & 0.12 & 0.07 \\
\cline { 2 - 5 } & HA & 28.99 & 29.93 & 26.72 \\
\cline { 2 - 5 } & LA & 21.34 & 22.53 & 21.86 \\
\cline { 2 - 5 } & SH & 49.54 & 47.54 & 50.9 \\
\hline & VG & 0.13 & 0.001 & 0.53 \\
\hline
\end{tabular}

The results for Point 2A, which is located outside of Nevada Solar One at a distance of $1500 \mathrm{~m}$ from Point 1A, show that the endmembers fractions were not affected by solar-facility construction (Figure 11). In other words, the mean value of the endmember fractions for preinstallation, syn-installation, and post-installation did not change significantly (Table 2). In Point 2A, low-albedo had the highest fraction and vegetation had the lowest fraction. The low value of the vegetation fraction seems logical because the facility is located in an arid area with a low 
481 amount of vegetation. In addition, the dominant land-cover type in the area is shrubland and

482 barren, which is represented as a combination of mostly low-albedo, high-albedo, shadow, and a 483 small amount of vegetation.

484 The time series plot of endmember types at Point 1A, located inside Nevada Solar One, 485 showed different behavior (Figure 10). The low-albedo fraction increased after the construction, 486 and decreased during the construction. Furthermore, the high-albedo fraction increased during 487 construction, and then slightly decreased after the installation of the solar panels. Similarly, the 488 shadow fraction decreased after construction; again, there was no significant change for the 489 vegetation fraction for pre-construction and post-construction. Solar panels are relatively dark 490 objects, and are constructed to absorb sunlight. Thus, a slight reduction of high-albedo and 491 increase of low-albedo was expected after construction. During construction, because the surface 492 is being prepared for installation of the solar panels, shrub removal, the land cover would be bare 493 soil, which is brighter when compared to shrubland. Therefore, high-albedo is increased and low494 albedo is decreased during the construction phase.

495 Figure 12 and 13 show similar results for the Nellis Solar Power Plant. Figure 12 shows 496 the changes for the time series of the endmember types for Point 1B within the facility's area, 497 and Figure 13 for Point 2B outside of the facility. The low-albedo fraction increased and the 498 high-albedo fraction decreased after construction at Point 1B within the facility (Table 2). The 499 shadow fraction decreased slightly after the construction, and the fraction of vegetation was close 500 to zero before and after the construction at Point 1B. Figure 13 displays the time series of the 501 endmember changes at Point 1B, which was located $850 \mathrm{~m}$ from Point $2 \mathrm{~B}$. According to the 502 plots, the endmember fractions in areas outside of the facility did not change significantly by the 503 construction of the solar facility. 
In order to compare the endmember fractions during pre- and post-construction in the

505 entire area, the mean value of each endmember fraction in each pixel for pre-construction was

506 subtracted from the post-construction value of that pixel. Figure 14 show the results for Nevada

507 Solar One and Figure 15 for the Nellis Solar Power Plant. The following equation summarizes

508 the operation:

$$
\Delta F=F_{\text {pre }}-F_{\text {post }}
$$

509 Where $\Delta F$ is image of land cover change, $F_{p r e}$ is the mean value of endmember fraction for pre-

510 construction, and $F_{\text {post }}$ is the mean value of endmember fraction for post-construction.

511 In Figures 14 and 15, the gray color represents a zero value, which means that no changes

512 occurred in those pixels between pre- and post-construction in terms of the corresponding

513 endmember type. Moreover, darker color indicates lower values, which represent an increase of

514 the fraction after the installation. Similarly, brighter color indicates higher values, which means

515 that the fraction of the endmember decreased after construction. It can be seen that the color of

516 the pixels that include solar panels for low-albedo is darker than any other areas (Figures 14 and

517 15), which means that the fraction of low-albedo surface increased after construction. The plant

518 borders are relatively bright because the soil had been disturbed; however, no solar panel was

519 installed there to absorb the light and increase the low-albedo. Equally, the colors of bordering

520 pixels are darker than other areas in high-albedo, which indicates an increase of high-albedo

521 fractions. It shows that disturbed or bare soil reflects the sunlight more than the solar panels. 
a

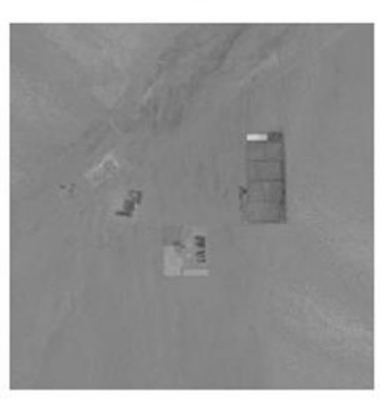

c

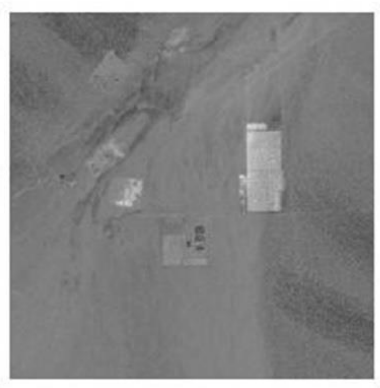

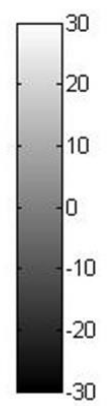

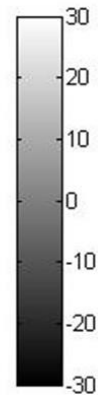

b

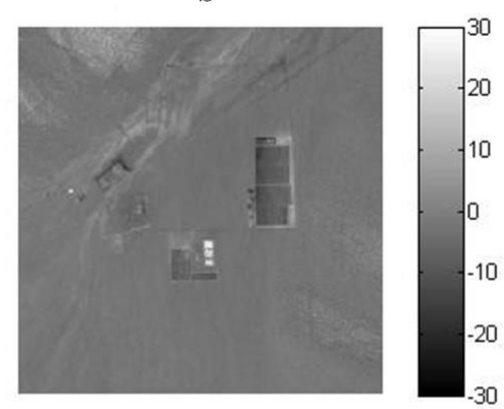

d

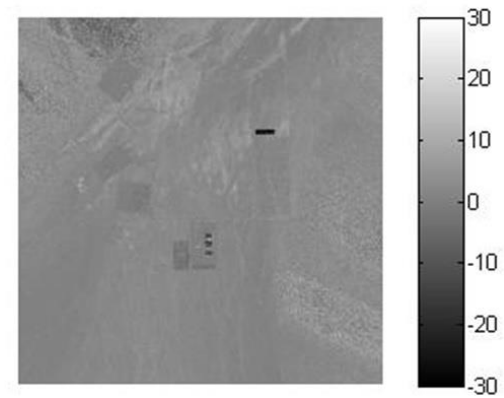

523 Figure 14. Mean difference of pre- and post-installation at Nevada Solar One for a) highalbedo, b) low-albedo, c) shadow, and d) vegetation.

a

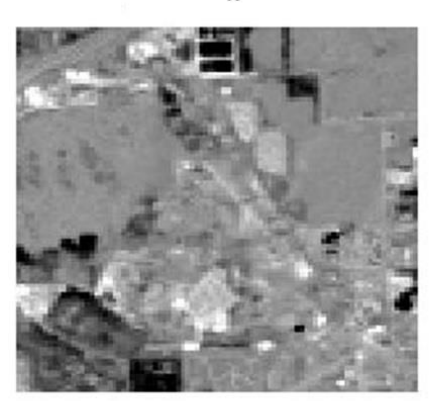

c

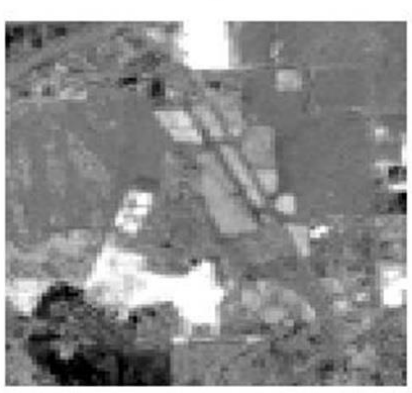

b
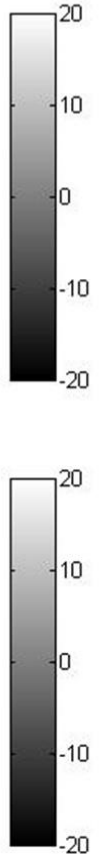

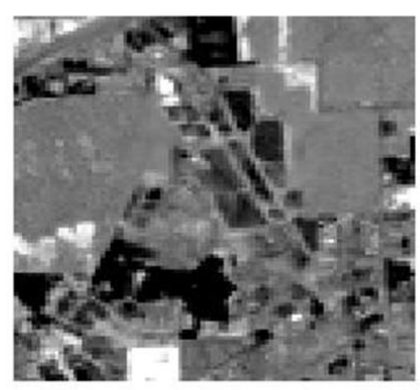

d
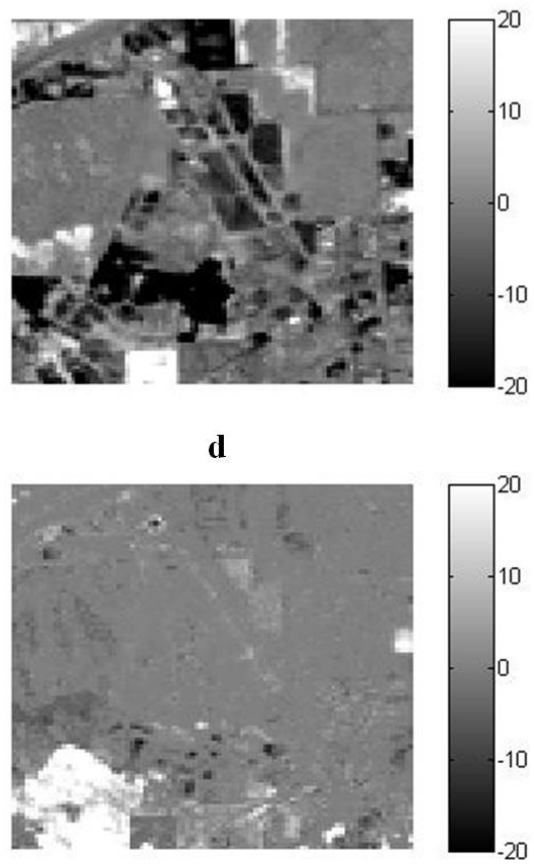

526 Figure 15. Mean difference of pre- and post-installation at the Nellis Solar Power Plant for a) 
Moreover, in the shadow images, the solar panels areas are brighter than other areas. The

530 decrease in the shadow fraction occurred due to installation of the solar panels. According to

531 Figure 7, the correlation coefficient of shadow was low; thus, the shadow fraction images do not

532 have high accuracy. Generally, in Nevada Solar One, rows of parabolic concentrators with

533 mirrors are used to exploit the sun's energy. Because the concentrators track the sun's location,

534 they are built at regular spaces to catch the sunlight with the maximum efficiency. Thus, it is

535 expected that shadow exists in the distance between the concentrators. In contrast, the Nellis

536 Solar Power Plant uses photovoltaic solar panels. In this case, the solar panels were installed

537 separately (not in rows) and relatively close to each other. Therefore, the fraction of shadow in

538 the area of the Nellis Solar Power Plant should be less than for Nevada Solar One.

539 Vegetation fractions did not change significantly from pre- to post-construction.

540 Consequently, the color of the endmember image for vegetation, which represents changes due

541 to solar-facility construction are almost the same all over the areas, and even the facilities are

542 relatively hard to distinguish in Figures 14 and 15. The reason is that the facilities were

543 constructed in arid areas, therefore, the amount of vegetation is negligible from the beginning of

544 construction onwards. According to Figures 14 and 15, it was expected that this method will

545 reveal a halo of impacted pixels in the immediate vicinity of solar installations. The output

546 revealed no such halo. Nevertheless, we conjecture that such effect will be profound in areas

547 with higher vegetation. It means that, based on the aforesaid analysis, the effect of solar facility

548 construction on land-cover patterns in neighboring area is negligible in this area (especially

549 Figure 14 that shows NS-1 which has been built outside the urban area). 


\section{6. Summary and Conclusions}

552 In this paper, the effect of two USSE installations on land cover in an arid environment was

553 studied. This study was conducted at Nevada Solar One and the Nellis Solar Power Plant in the

554 southwest region of the U.S., both installed within the last decade. The effects were measured 555 using changes in the land-cover types surrounding and within each facility.

556 Two common methods for spectral data treatment were tested: principal component 557 analysis (PCA) and minimum noise fraction (MNF). According to the validation process, PCA558 Normalized and MNF-Original datasets were selected as the data-preparation method. Land559 cover types were defined based on a two-band scatter plot of pixels. The common endmembers 560 in all the scatter plots were determined as high-albedo, low-albedo, shadow, and vegetation. In 561 order to understand effect of solar facility construction on the environment, the changes for land562 cover trends were compared using pre- and post-installation land-cover fractions.

563 SMA was applied on PCA-Normalized and MNF-Original of Landsat 5 TM images from 5642004 to 2011 in the two areas. The average percentage error plot for PCA-Normalized and MNF-

565 Original in Nevada Solar One area and the Nellis Solar Power Plant showed that the PCA-

566 Normalized method had a higher accuracy. Land-cover analysis of the points located close but

567 outside of the facilities (Point 2A and Point 2B) showed that the mean value of endmember 568 fractions for pre-installation, syn-installation, and post-installation did not change significantly.

569 On the other hand, results of land-cover analysis of the points located within the facility showed

570 that the low-albedo fraction increased and the high-albedo fraction decreased after construction.

571 The shadow fraction decreased slightly after construction, and the fraction of vegetation was

572 close to zero before and after the construction, due to the plants being constructed in an arid area. 
574 cover trends in arid environments. The results might be different in other areas, especially where

575 the vegetation fraction was higher. In addition, endmember types that indicated that various

576 classes of land-cover types could be different in other studies. For example, low-albedo could

577 represent water bodies and asphalt, even low these two land-cover types could be defined

578 individually as endmembers. This study indicated that except for the long-term effects of USSE

579 plants on the environment, land-cover patterns in the case of high-albedo, low-albedo, shadow,

580 and vegetation altered significantly inside the solar plant areas.

581 Due to increasing trends in USSE plant construction, it is important to understand its

582 short- and long-term effects on the environment and land cover. The significance of this research

583 is determination of land-cover change caused by construction of USSE plants. It provides useful 584 insight into their effects on land cover at two plants in Nevada.

586 Acknowledgement

587 This material was based upon work supported by the National Science Foundation under Grant 588 No. IIA-1301726.

589 Appendix A. Table of acronyms

$590 \quad$ CDR

$591 \quad$ CSP

$592 \quad \mathrm{DN}$

$593 \quad$ HA
Climate data record

Concentrating solar power

Digital numbers

High albedo 
594 LA

595 LCA

596 MNF

$597 \quad$ NAIP

$598 \quad$ NS-1

$599 \quad \mathrm{NSPP}$

$600 \quad$ PCA

$601 \quad$ PV

602 RGB

$603 \quad \mathrm{SH}$

604 SMA

605 TM

606 TOA

607 USSE

$608 \quad$ VG

609
Low albedo

Life-cycle assessment

Minimum noise fraction

National agriculture imagery program

Nevada solar one

Nellis solar power plant

Principal component analysis

Photovoltaic

Red green blue

Shadow

Spectral mixture analysis

Thematic mapper

Top-of-atmosphere

Utility-scale solar energy

Vegetation 
611 [1] 2014 Top 10 Solar States | SEIA n.d. http://www.seia.org/research-resources/2014-top-10612 solar-states (accessed November 13, 2015).

613 [2] Hernandez RR, Easter SB, Murphy-Mariscal ML, Maestre FT, Tavassoli M, Allen EB, et 614 al. Environmental impacts of utility-scale solar energy. Renew Sustain Energy Rev 2014;29:766-79. doi:10.1016/j.rser.2013.08.041.

616 [3] Devabhaktuni V, Alam M, Shekara Sreenadh Reddy Depuru S, Green RC, Nims D, Near 617 C. Solar energy: Trends and enabling technologies. Renew Sustain Energy Rev $618 \quad$ 2013;19:555-64. doi:10.1016/j.rser.2012.11.024.

619 [4] Phillips J. Determining the sustainability of large-scale photovoltaic solar power plants. 620 Renew Sustain Energy Rev 2013;27:435-44. doi:10.1016/j.rser.2013.07.003.

621 [5] Tsoutsos T, Frantzeskaki N, Gekas V. Environmental impacts from the solar energy technologies. Energy Policy 2005;33:289-96. doi:10.1016/S0301-4215(03)00241-6.

[7] Klein SJW, Rubin ES. Life cycle assessment of greenhouse gas emissions, water and land use for concentrated solar power plants with different energy backup systems. Energy Policy 2013;63:935-50. doi:10.1016/j.enpol.2013.08.057.

[8] Turney D, Fthenakis V. Environmental impacts from the installation and operation of largescale solar power plants. Renew Sustain Energy Rev 2011;15:3261-70.

632 [9] Horner RM, Clark CE. Characterizing variability and reducing uncertainty in estimates of 
solar land use energy intensity. Renew Sustain Energy Rev 2013;23:129-37. doi:10.1016/j.rser.2013.01.014.

635 [10] Murphy DJ, Horner RM, Clark CE. The impact of off-site land use energy intensity on the overall life cycle land use energy intensity for utility-scale solar electricity generation

[11] Hernandez RR, Hoffacker MK, Field CB. Land-use efficiency of big solar. Environ Sci technologies. J Renew Sustain Energy 2015;7:033116. doi:10.1063/1.4921650. Technol 2014;48:1315-23. doi:10.1021/es4043726.

[12] Chiabrando R, Fabrizio E, Garnero G. The territorial and landscape impacts of photovoltaic systems: Definition of impacts and assessment of the glare risk. Renew Sustain Energy Rev 2009;13:2441-51. doi:10.1016/j.rser.2009.06.008.

[13] Armstrong A, Waldron S, Whitaker J, Ostle NJ. Wind farm and solar park effects on plantsoil carbon cycling: Uncertain impacts of changes in ground-level microclimate. Glob Chang Biol 2014;20:1699-706. doi:10.1111/gcb.12437.

[14] Gunerhan H, Hepbasli A, Giresunlu U. Environmental Impacts from the Solar Energy Systems. Energy Sources, Part A Recover Util Environ Eff 2008;31:131-8. doi:10.1080/15567030701512733.

[15] Hernandez RR, Hoffacker MK, Field CB. Efficient use of land to meet sustainable energy needs. Nat Clim Chang 2015;5:353-8. doi:10.1038/nclimate2556.

654 [17] Beylot A, Payet J, Puech C, Adra N, Jacquin P, Blanc I, et al. Environmental impacts of 655 large-scale grid-connected ground-mounted PV installations. Renew Energy 2014;61:2-6. 
doi:10.1016/j.renene.2012.04.051.

[18] Qian C. Impact of land use/land cover change on changes in surface solar radiation in eastern China since the reform and opening up. Theor Appl Climatol 2014:1-9. doi:10.1007/s00704-014-1334-5.

[19] Chen W, Sakai T, Moriya K, Koyama L, Cao CX. Estimation of Vegetation Coverage in Semi-arid Sandy Land Based on Multivariate Statistical Modeling Using Remote Sensing

[20] Mahtta R, Joshi PK, Jindal AK. Solar power potential mapping in India using remote Data. Environ Model Assess 2013;18:547-58. doi:Doi 10.1007/S10666-013-9359-1. sensing inputs and environmental parameters. Renew Energy 2014;71:255-62.

[21] Calvert K, Pearce JM, Mabee WE. Toward renewable energy geo-information doi:10.1016/j.renene.2014.05.037.

infrastructures: Applications of GIScience and remote sensing that build institutional capacity. Renew Sustain Energy Rev 2013;18:416-29. doi:10.1016/j.rser.2012.10.024.

[22] Lu D, Weng Q. Spectral Mixture Analysis of the Urban Landscape in Indianapolis with Landsat ETM + Imagery. Photogramm Eng Remote Sens 2004;70:1053-62.

[23] Wang W, Yao X, Ji M, Zhang J. Spectral data treatments for impervious endmember derivation and fraction mapping from Landsat ETM+ imagery: a comparative analysis. Front Earth Sci 2014. doi:10.1007/s11707-014-0456-5.

[24] Mei S, He M, Wang Z, Feng D. Spatial Purity Based Endmember Extraction for Spectral Mixture Analysis. IEEE Trans Geosci Remote Sens 2010;48:3434-45. doi:10.1109/TGRS.2010.2046671.

[25] Plaza A, Martinez P, Perez R, Plaza J. Spatial/spectral endmember extraction by multidimensional morphological operations. IEEE Trans Geosci Remote Sens 
2002;40:2025-41. doi:10.1109/TGRS.2002.802494.

680 [26] Song C. Spectral mixture analysis for subpixel vegetation fractions in the urban environment: How to incorporate endmember variability? Remote Sens Environ 2005;95:248-63. doi:10.1016/j.rse.2005.01.002.

683

[27] Nevada

Solar

One

n.d.

http://www.acciona-

energia.com/activity_areas/csp/installations/nevadasolarone/nevada-solar-one.aspx (accessed November 13, 2015). http://www.nellis.af.mil/library/nellissolararray.asp (accessed November 13, 2015).

[29] Rogan J, Franklin J, Roberts DA. A comparison of methods for monitoring multitemporal vegetation change using Thematic Mapper imagery. Remote Sens Environ 2002;80:143-

[30] Thomlinson JR, Bolstad P V., Cohen WB. Coordinating methodologies for scaling 56. doi:10.1016/S0034-4257(01)00296-6. landcover classifications from site-specific to global: Steps toward validating global map

694 [31] Jomaa I, Auda Y, Saleh BA, Hamze M, Safi S. Landscape spatial dynamics over 38 years

[32] Chander G, Markham BL, Helder DL. Summary of current radiometric calibration coefficients for Landsat MSS, TM, ETM+, and EO-1 ALI sensors. Remote Sens Environ 2009;113:893-903. doi:10.1016/j.rse.2009.01.007. 
702 [34] Home: W.M. Keck Earth Sciences \& Mining Research Information Center n.d. 703 http://keck.library.unr.edu/ (accessed November 13, 2015).

704 [35] Johnson PE, Smith MO, Adams JB. Quantitative analysis of planetary reflectance spectra $705 \quad$ with principal components analysis. J Geophys Res Suppl 1985;90:805 - .

706 [36] Johnson RA, Wichern DW. Applied Multivariate Statistical Analysis. 1992. 707 doi:10.1198/tech.2005.s319.

708 [37] Green AA, Berman M, Switzer P, Graig MD. A transformation for ordering multispectral 709 data in term of image quality with implications for noise removal. IEEE Trans Geosci $710 \quad$ Remote Sens 1988;26:65-74.

711 [38] Boardman JW. Geometric mixture analysis of imaging spectrometry data. Geosci Remote 712 Sens Symp 1994 IGARSS ’94 Surf Atmos Remote Sens Technol Data Anal Interpret Int 1994;4:2369-71. doi:doi:10.1109/IGARSS.1994.399740.

714 [39] Elmore AJ, Mustard JF, Manning SJ, Lobell DB. Quantifying Vegetation Change in 715 Semiarid Environments. Remote Sens Environ 2000;73:87-102. doi:10.1016/S0034-

717 [40] Wu C, Murray AT. Estimating impervious surface distribution by spectral mixture analysis. Remote Sens Environ 2003;84:493-505. doi:10.1016/S0034-4257(02)00136-0.

719 [41] Canty MJ. Image analysis, classification and change detection in remote sensing: With 720 algorithms for ENVI/IDL. second edi. CRC Press; 2010.

721 [42] Lagarias JC, Reeds J a., Wright MH, Wright PE. Convergence Properties of the Nelder-722 Mead Simplex Method in Low Dimensions. SIAM J Optim 1998;9:112-47. $723 \quad$ doi: $10.1137 /$ S1052623496303470. 